\title{
6. A portent of things to come: lessons from a reforming minister
}

\author{
The Hon. Lindsay Tanner
}

This contribution was written during the 2010 election campaign-a period when some commentators were suggesting the age of reform was over. Indeed, the first half of 2010 saw a series of extraordinary events that punctuated what perhaps would otherwise have been a steady period of reform progress in Australia. But these should not be viewed as a portent of things to come.

I was directly involved in reform efforts over the past three years in my capacity as Minister for Finance, and indirectly as a shadow minister for a much longer period. Shadow ministers have a bigger influence than many people think, because by merely defining the theatre of political combat, they and their party can play a significant role in our system. For example, what they choose to oppose the government on, what messages they choose to convey and whether they choose to be creative or simplistic all help define how Australian politics unfolds.

Of all the reform efforts I was involved in as a minister, this chapter will focus on two of the more interesting and significant: first, the process of harmonising and reforming regulation across Australia through the Council of Australian Governments (COAG) business regulation and competition working group; second, the roll-out of the National Broadband Network. I have chosen these two reforms because in very different ways they provide some important lessons for people who are interested in working out how to make things actually happen, rather than merely looking like you are making things happen without doing it, which unfortunately is the dominant dynamic of modern politics.

\section{Reforming the federation: the COAG working group on business regulation and competition}

Consider first the COAG working group on business regulation and competition. The genesis of the competition and business regulation reform agenda dates from December 2007, when under the auspices of the Prime Minister, the premiers and chief ministers met to focus on one primary objective: the harmonisation of regulatory regimes across every state and territory. This was to be no mean feat, as Australia's range of regulatory frameworks was extremely diverse, with some broad and far-reaching, but others very specific, with a focus on particular sectors or particular activities. 
Twenty-seven items in the field of competition and business regulation were identified for reform and put on the agenda by COAG. Of course, being 'put on the agenda' does not imply that anything might happen, nor that anybody might actually do anything after they leave the meeting. Indeed, for many politicians, putting items on the COAG agenda serves merely as a symbolic device. Everybody involved can return to their respective constituencies and tell them that yes, the item in question is being dealt with because it is on the COAG agenda. And should anybody be so rude as to inquire what 'on the COAG agenda' actually means (which usually they are not), such politicians can resort to glib rhetoric and gobbledygook, which confuses the average person so much that they give up.

The 27 items COAG identified covered areas of concern where no progress was being made. Examples include occupational health and safety legislation, trade licensing (for example, for plumbers and electricians), personal properties security registration, environmental assessment processes, the building codes that apply around the country, rail safety laws, heavy transport laws, laws governing food labelling, laws governing chemicals and plastics, financial services (for example, the nationalisation of regulation of trust companies and margin lending), and so on.

This is just a small sample of the issues that in aggregate covered a substantial portion of total economic activity across Australia. And when we looked at each of these, what we found is a patchwork of regulatory regimes and arrangements across the country, sometimes contradictory, sometimes non-compliant. For example, in the area of food labelling, it was physically impossible for a company to produce a product that complied with regulations all around the country, because to be compliant in South Australia, for instance, automatically made it non-compliant in Victoria, and vice versa. The end result was that if producers wanted to sell their products nationally, they must produce different versions or different labels for different jurisdictions.

Thus, since its creation in 2007, the COAG working group on business regulation and competition has slowly and methodically worked through each item, in the process always inching the agenda forward. It has been a particularly interesting exercise insofar as the group is populated by senior officials of Treasury and the Finance Department, but, until recently, co-chaired by two federal politicians, Craig Emerson and myself. And, much to my amazement, all 27 areas for reform are still broadly on track. At the outset, I said privately to Craig Emerson that if, at the end of the process, 20 of the areas had been addressed, I would be satisfied. That appraisal now seems like an underestimation. And while there have been instances of slippage during those three years (for example, state and territory elections can delay the process), overall the reform process remains on track. 
It will, however, take several years more until all 27 problem areas have been addressed. Why? Because first and foremost, what is required in this reform process is to reach 'in principle' agreement about what is going to occur. That could involve a single national scheme, or it could be a template piece of legislation in an individual state that other states and territories agree to implement by reference, thus creating an identical regime across the federation. Similarly, it could be mutual recognition, or it could be harmonisation. There is a variety of possibilities, often involving line agencies and line ministers.

Further, once in-principle agreement has been achieved, the process still has several stages ahead of it. First consideration must be given to the 'detail', which can be challenging. Then it must pass through individual cabinets - eight or nine of them, in most cases. Next it will usually end up on a legislative program, and once it has passed through a lower house, it must finally pass through an upper house. And although this last problem does not apply to Queensland, the Northern Territory and the Australian Capital Territory, everywhere else it does. In total, this then represents a lengthy process, and of course inevitably during various points of that process there has to be some degree of consultation with stakeholders. Thus, it is a reform process that is quite protracted.

One danger when pursuing the harmonisation of laws across the country is the tendency to race to the bottom or move to the lowest-common-denominator law. This danger arose in a number of the 27 areas. There is always a temptation to default to the easiest position under pressure from both ends of the regulatory spectrum. At one level, businesses quite validly say to us 'look, we don't want you to end up simply dragging everybody up to the most intrusive, most burdensome regulatory arrangement that applies. We don't want to be harmonised up.' Equally, we did not want to do the reverse, which was to default to whoever had the weakest laws and the lowest costs, because nobody would accept that. Consequently, it means that in some cases you enter some very complex negotiations.

A classic example of this is the unfair-contracts arrangements in consumer law, where Victoria had a much more rigorous regime than most other states. We had commissioned a Productivity Commission inquiry into this area, which had come up with a compromise model. It was not quite as strict as the Victorian arrangement, but for many states it meant that if they adopted it, it was going to become substantially more rigorous than what had prevailed previously. Consequently, the Commonwealth ended up in a position that was tricky to navigate. Chris Bowen was the line minister directly responsible for consumer law, and did a good job navigating it through the ministerial shoals across the various jurisdictions. We finished with something that is not exactly the same as the Productivity Commission proposition, but not totally dissimilar. The end result is we got criticism from the consumer movement for stepping back from the strict Victorian regime at one end, and criticism from business for strengthening consumer-protection laws in unfair contract provisions everywhere else. 
You also have to maintain broad stakeholder support or tolerance for the reform directions. In the area of occupational health and safety laws, New South Wales had the toughest laws, with criminal penalties that business was completely freaked out about. If the Commonwealth had said we are going to make the NSW laws the template across the country, business groups would have then replied 'no, we will stick with the ramshackle variety we currently have'. Backsliding would have occurred.

Finally, in order to keep the COAG reform process on target, the working group established key milestones to drive progress. There was, for example, a detailed analysis in each case involving individual milestones to be achieved on a sixmonthly basis; so by December 2010 we would aim to reach a certain stage, then by July 2011 another, and so on. Generally, these milestones were met.

\section{Reform lessons from the COAG review process}

I have learned a number of significant lessons from my experience in the COAG working group on business regulation and competition. First, the real enemy is inertia. One of the great lessons I have learned from being a minister - having been a shadow minister for such a long time - is that government is finite. It might look infinite when you are in opposition with one or two advisors, up against the department with 1500 people and a ministerial office with 10 or 15 people in it, but in reality government is finite. There is only so much time in the day and so much capacity to deal with issues, so many key people who can absorb challenging questions, deal with pressing issues, make decisions and implement them. As a result, either overtly or by accident, the reformer must make priority choices, with less important issues simply falling by the wayside.

So it is with the 27 areas identified by COAG for reform. The principal reason there had been no action to address them previously was systemic inertia - the fact that nobody had got around to doing anything about them. While politicians might have made noises about reforming these areas and occasionally business organisations complained about some of the particular issues, the truth was that nobody had been motivated enough to say 'we are going to make this happen'.

Even when reformers are actually pursuing a reform agenda, inertia can still be a problem. It takes a huge application of political will to maintain momentum and motivation, to keep the blowtorch to the belly of all those involved, and to galvanise a state or territory into reaction if it is lagging behind in a particular reform endeavour. Without such application, will and energy, a reform process will simply fade away over time. 
Obviously, elections are a major cause of reform inertia. At any given time in Australia there will be an election happening somewhere, or sufficiently close to disrupt the ordinary business of government. Consequently, a reformer trying to gain the cooperation of every government in Australia with a particular reform program is always susceptible to being disrupted by an impending election, or indeed an election that is happening, or that has just happened.

In fact, in the majority of regulatory cases that I was dealing with during this reform process, inertia proved a greater obstacle than any serious vested interest opposition to what we were setting out to achieve. In the odd case there were minor issues to be tweaked, but most of the time the various interests involved were reasonably constructive, as we were not tackling problems where there were huge institutional barriers to reform.

A second salient lesson I have learned from this reform process is the complications that can arise from the variations across state boundaries. Consider the following examples to illustrate how complex things can get. Buying a car in Australia generally involves national organisations financing your purchase through a system of personal properties security registration. In essence, the nature of the activity does not vary across the country; after all, buying a new car, or a speedboat, is largely the same process, be it in Perth, Melbourne or Sydney. Consequently, you could be forgiven for thinking that setting up a national register to replace the existing state and territory arrangements would not be overly difficult. That is initially what I thought, until we stumbled across the fact that the fees that are currently paid-or were paid-varied enormously according to each jurisdiction. For example, some states such as Western Australia ran on the basis of cost recovery, while others such as New South Wales had arrangements according to which the fees were much larger, and were hypothecated to their fair-trading regime. As a result, the fees for personal property securities registration were being hypothecated to help fund Consumer Affairs inspectors and officers in Dubbo, Newcastle or wherever.

Unsurprisingly, this situation creates a stand-off; each side looks at this and says (in the case of Western Australia) 'we don't want to put our fees up', and (in the case of New South Wales) 'well, we don't want to put our fees down, because that leaves a hole in our budget'. An impasse prevails. And of course, as a way of ending that impasse, both parties put their hands out to the Commonwealth for financial aid. I am bitter and twisted about those issues because basically that is the default position of almost everybody in public life. Being Finance Minster, you feel the pointy end of it.

Such is the prevalence of this problem that when I used to have one-on-one meetings at community cabinet, I would jokingly suggest that we could save a lot of useless dialogue by allocating everybody a piece of cardboard that says 
'give me money', and they could walk up in front of me and hold it up. This federalism-related complication is a classic example of a problem that was not immediately apparent until we really dug into the issue. Then of course we did have to come to the rescue with some incentives, at least for the initial period.

Another illustration of the problems that arise from state and territory variations became apparent when we tackled the issue of harmonising food-safety standards. This happened when we reached an agreement with the states, territories and New Zealand according to which a common regulatory framework would be created, but enforcement would remain in the individual state, territory, and New Zealand jurisdictions. Superficially, that sounded entirely reasonable; the Commonwealth did not have the infrastructure or the expertise to be on the ground inspecting or enforcing such laws. And yet, in this case, as in many others, a great deal depends on the interpretation of extremely obscure aspects such as what particular levels of chemicals might apply and so forth.

So, while we were able to create a formal regulatory structure specifying the types and levels of ingredients that could go into food, the reality was that a great deal of decision making occurred below that level at the discretion of the various inspectorates. Often these inspectorates had developed an extensive culture of protocols or arrangements through which they were actually telling manufacturers what they may and may not put in products. We then immediately came up against the challenge of ensuring there was jurisdictional harmony across decision making by the enforcers, which made the whole process infinitely more complex.

A third lesson from our experience with the 27 items on the COAG regulatory reform agenda was that there is huge benefit in doing these things as a 'job lot', not one-by-one. When you do these things on a one-off basis, you tend to force people to retreat to absolutist positions, whereas if you have a whole range of things going on at the same time, and they are broadly going through the same mechanisms, you have the capacity for implicit give and take, which broadens your scope to get good outcomes. In other words, by working across a number of areas simultaneously, the scope for negotiation between the jurisdictions becomes more three-dimensional.

Individual states implicitly understand that if they take a 'dive' on this issue then the odds are pretty good that somewhere else they are going to get looked after, and it will be somebody else who has to take the 'dive'. While I have no evidence that any explicit horse-trading or deal making was entered into, I have no doubt that the constructive tenor of the approach that all states and territories took was influenced by the knowledge that there were swings and roundabouts. Hence, in some respects, probably the most important lesson of all out of this is to have a broad canvas, and have lots of moving parts, because that 
gives you the maximum opportunity to keep everybody onboard. It is important that everybody thinks they are getting a reasonable deal in the totality, even if they have lost some important items along the way.

The fourth lesson I have learned during this reform process is the importance of central agencies in government to set and keep pushing the agenda. I was so impressed by their endeavours that I took to calling the business regulation and competition working group of COAG the 'central agencies club'. What is especially valuable about such agencies is the presence of senior experts who are seriously committed to reform. Such figures actually have responsibility for the big picture and want to oversee productivity improvements and the accession of genuinely national harmonised regulatory arrangements. In contrast, people in line agencies often do not share that perspective, and nor should they, as that is not their prime responsibility. As a result, if you are running the Department of Transport in South Australia, for example, your job is to worry about safety on South Australia's roads. It is not your job to worry about broader productivity issues or inter-jurisdictional harmonisation; productivity interstate is far removed from your responsibilities.

Accordingly, it is crucial to have central agency buy-in, and in this case we had central agencies driving the process. Moreover, the Prime Minister's decision to attach the deregulation responsibility to the Department of Finance was a wise move, as it put this agenda at the heart of government, not to mention at the heart of that so-called 'central agencies club'. Such a move was instrumental in driving this agenda.

The fifth lesson has been the important role of the Business Council of Australia. Every time I met with them over the past few years, I kept encouraging them to continue hitting the front pages of the Australian Financial Review, as there is nothing like external pressure to push issues up the political agenda. Subsequently, their role, and to some degree that of some other employer organisations and business organisations, has been crucial in keeping the issue in the public eye, and thus ensuring we are still actually doing things.

This is the great challenge in this reform endeavour: how do we popularise and get wider engagement amongst the community with these kinds of issues, especially if their content innately makes it difficult to attract attention? The best answer I could come up with was to point out in every speech I made on the subject that people in New South Wales are quite happy for me to drive on their roads and rely on Victorian authorities to tell them that I will probably drive safely and responsibly. But, if I were a Victorian plumber, they would not allow me to fix their toilets without sitting for a licence exam for plumbers in New South Wales. Clearly, it is a dangerous business fixing people's toilets, and one that is far riskier than driving on their roads. It is extremely difficult to 
popularise regulatory reforms of this kind because they are incremental, spread over so many activities, and because only a small number of people understand how important they are.

Despite these not insignificant challenges, the COAG business regulation and competition working group has thus far been outstandingly successful. Not only is it on track to achieve its reforms in the 27 specific areas, but it has also proved to be an effective working model for continuous cooperation and collaboration between the two levels of government, rather than occasionally coming together every six or 12 months. As a result of this working group, there is now an almost continuous dialogue going on across key players in the central agencies, both at a state and a federal level. This augurs well for future agendas, and provides a foundation for future reform.

\section{Telecommunications competition and the National Broadband Network initiative}

The second major reform I was involved in intimately over a reasonable period was the National Broadband Network (NBN). In 2002 I was shadow minister for communications, and, together with then Opposition Leader, Simon Crean, launched a telecommunications reform agenda. At the heart of this major policy statement was the concept of structurally separating Telstra's business activities from its retail services. To impose a structural separation would enhance transparency and improve competitiveness. At the time this was considered a somewhat radical proposition; the idea had been touted by various quarters for quite a long time, but this was the first time that either side of politics had seriously put it on the political agenda. Steven Conroy replaced me as the shadow communications minister in 2004, and since that time the two of us have focused relentlessly on one core objective in telecommunications: getting the industry structure right.

Telecommunications is today almost as important to our economy as financial services. It is becoming equally as significant to the lifeblood of economic activity as moving money around. And yet, because of the Howard Government's obsession with privatisation and its failure to deal first with issues of industry structure that would have created a genuinely competitive industry arrangement, we ended up with a situation where Telstra as a private monopoly was too powerful for any government to effectively regulate. One need only consider the problematic relationship between Sol Trujillo and the Howard Government as an example. As a consequence, rather than liberating its enormous capabilities for innovation, risk-taking, and being a world leader in its field, Telstra instead focused its creativity, energy and dynamism on gaining the regulatory regime 
and squashing competition and innovation. Telstra accounted for two-thirds of our entire telecommunications industry and yet the protective regulatory structure in place skewed all the incentives in the wrong direction.

I do not blame Telstra for that. Throughout the past decade and a half, under different leadership, the company made decisions in the interest of its shareholders, and as the management of the Telstra Board saw fit. I do, however, blame the Howard Government for failing to address these issues, and then finding itself in a position where the roll-out of broadband (principally using high-speed coax cable) in Australia was significantly behind many comparable countries, whether in terms of access, speed, price, or any other facet. This was because under the Howard Government's industry structure for the telecommunications sector, the dynamics were all skewed against rapid technological change, rapid innovation and the development of new products.

The National Broadband Network is designed to address this problem. It is not just a piece of infrastructure - huge though it is in that context. Rather, it is also a giant reform agenda that is about creating a genuinely level playing field in Australian telecommunications. Incidentally, I believe Telstra would continue to do extremely well on such a playing field, as the company's emphasis would shift from lawyers gaining regulations to more innovation, better marketing, better product development and competing from a position of genuine strength.

When I started pursuing it, the idea of a structural separation for Telstra was considered something of a fringe position. I was initially unable to garner any serious interest or support from organisations such as the Business Council of Australia or the Australian Chamber of Commerce and Industry; they were happy to berate Labor for its perceived failings on economic reform in certain specified areas such as industrial relations, but when it came to the need for serious reform in telecommunications - of fundamental importance to most if not all of their constituency - they were not forthcoming.

Further, because there was not much academic research being conducted into these issues, there was a virtual vacuum in the public-policy world about them. Graham Samuel and the Australian Competition and Consumer Commission (ACCC) were enormously important in their support, although because they are not a public-advocacy body they were constrained. Nonetheless, the commitment of the ACCC to following through on the national competition policy principles from 1995 was an ever-present pressure in the debate that always helped to focus attention on the problem.

Nor, paradoxically, was the media significantly interested in the issue. The Australian and the Australian Financial Review would occasionally cover the topic, only to forget about it for extended periods. The Age proved more 
interested in the telecommunications sector, but was relentlessly anti-reform, giving regular coverage for people such as Kevin Morgan and Ken Davidson, who do not believe there is a problem and think that competition is not a significant matter in areas such as telecommunications.

In spite of these challenges, in perhaps ways that nobody anticipated, we have progressed to a point where a new world of genuinely competitive world-class telecommunications is going to be available for Australia, and for Australian businesses. And the bill to separate Telstra should pass in the next Parliament.

\section{Reform lessons from telecommunications and the NBN}

The lessons from the telecommunications reforms are: first, build a convincing case; second, focus on the deficiencies being experienced by ordinary people and ordinary businesses, which ultimately drove the impetus for reform; third, create champions wherever you can in the political world, policy communities and in the wider community. As a consequence of this last point, the demand for serious broadband has moved from the fringe information and communication technology (ICT) world into mainstream Australia, whether as consumers or as businesses. And finally, try to mobilise the interests that support you to be as active as they can in the public debate.

All of these points are significant lessons drawn from my experience in telecommunications reform. And yet, many challenges remain if we are to introduce high-speed broadband in Australia and transform our infrastructure from the digital dark ages.

The National Broadband Network is about breaking through the inertia and resistance to create a genuinely viable, competitive, innovation-driven and risk-driven piece of national infrastructure. Under this system all-comers from Telstra down will be able to compete on equal terms, and which retail provider becomes a commercial success will be determined by the provider's capacity to innovate, take risks, provide services people want and mobilise the necessary capital.

So, there is much genuine reform taking place in Australia, despite some media commentary suggesting the contrary. But unfortunately, the majority of these reforms are of the regulatory and procurement ilk, which is not the kind of issue that sells newspapers. Be assured, even if you are not reading about it in newspapers - do not be fooled-reform is happening out there. And there will always be the need for more reform as we progress into the future. 